\title{
Conhecendo um Programa de Liberdade Assistida pela Percepção de seus Operadores
}

Getting to Know an Assisted Liberty

Program by its Operators' Perception

Conociendo un Programa de Libertad Asistida por la Percepción de sus Operadores

Maria Emília

Passamani \&

Edinete Maria Rosa

Universidade Federal

do Espírito Santo

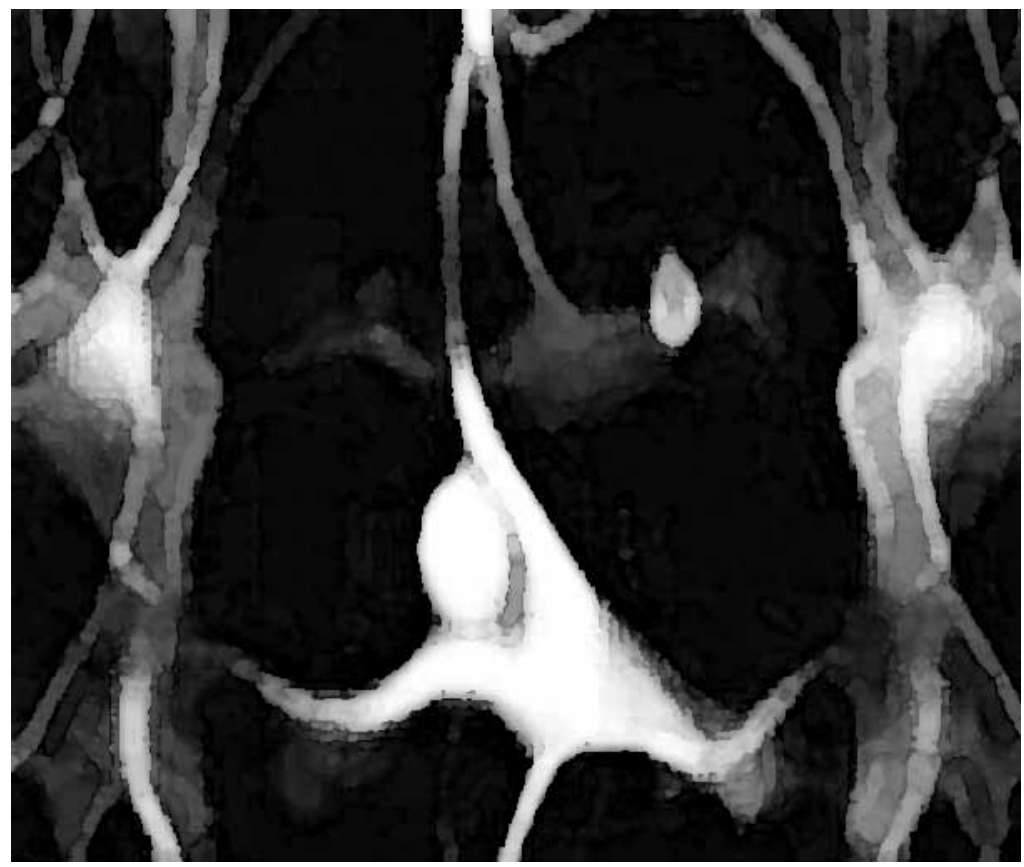


Resumo: Este artigo se baseia em pesquisa desenvolvida no mestrado em Política social, cujo objetivo foi conhecer a percepção que os operadores da medida socioeducativa de liberdade assistida comunitária Casa Sol Nascente têm a respeito do seu programa. Partimos do pressuposto de que esse programa tem sido positivo no acompanhamento aos adolescentes em conflito com a lei, na medida em que os atende em meio aberto, preservando a sua convivência familiar e comunitária, como é estabelecido pelo Estatuto da Criança e do Adolescente. O programa tem recebido boa avaliação dos participantes e de suas respectivas famílias, além de ter apresentado um índice de reincidência significativamente reduzido. Apresentamos os resultados mais relevantes organizados em categorias: o trabalho em equipe, os aspectos negativos e positivos do programa, os conceitos de adolescente e de adolescente em conflito com a lei, a proposta pedagógica e as concepções de emancipação, de ressocialização e de protagonismo juvenil que norteiam as atividades desenvolvidas no programa.

Palavras-chave: Liberdade assistida. Adolescentes em conflito com a lei. ECA. Programa socioeducativo.

Abstract: This article is based on research that aimed to know the perception the operators who work with the social-educative measures of the assisted liberty house Casa Sol Nascente have about their program, that has succeeded in following the adolescents in conflict with the law since it works with the teens in an open environment, preserving the conviviality of the family and the community, just as established by ECA. The program has been receiving good evaluation from its participants and families. The results will be presented based on some aspects which were considered more relevant in the interviews: the staff, the negative and the positive aspects of the program, the concepts of adolescence and of the adolescents in conflict with the law, the pedagogic proposal of the program, the conception of emancipation, ressocialization and teenage protagonism that guide the activities developed in the program.

Keywords: Assisted liberty. Adolescents in conflict with the law. ECA. Socioeducative program.

Resumen: Este artículo se basa en pesquisa desarrollada en el maestría en Política social, cuyo objetivo fue conocer la percepción que los operadores de la medida socioeducativa de libertad asistida comunitaria Casa Sol Naciente tienen a respeto de su programa. Partimos del presupuesto de que ese programa ha sido positivo en el acompañamiento a los adolescentes en conflicto con la ley, a medida en que se reúnen en medio abierto, preservando su convivencia familiar y comunitaria, como es establecido por el Estatuto del Niño y del Adolescente. El programa ha recibido buena evaluación de los participantes y de sus respectivas familias, además de haber presentado un índice de reincidencia significativamente reducido. Presentamos los resultados más relevantes organizados en categorías: el trabajo en equipo, los aspectos negativos y positivos del programa, los conceptos de adolescente y de adolescente en conflicto con la ley, la propuesta pedagógica y las concepciones de emancipación, de resocialización y de protagonismo juvenil que nortean las actividades crecidas en el programa.

Palabras clave: Libertad asistida. Adolescentes en conflicto con la ley. ECA. Programa socioeducativo.

A veiculação de notícias e as experiências negativas de trabalhos desenvolvidos com adolescentes em conflito com a lei têm estado constantemente em evidência na mídia, sendo questionador o fato de não se dar visibilidade às propostas positivas, bem-sucedidas, que apostam e investem nesses adolescentes por acreditarem na possibilidade de mudança nos rumos de suas vidas. Nesse contexto, decidimos estudar a experiência desenvolvida pelo Programa de Liberdade Assistida Comunitária Casa Sol Nascente, no Município de Serra, ES. Tínhamos algumas referências positivas do programa disponibilizadas em sites da Pastoral do Menor, tais como a sua proposta pedagógica, a dinâmica de trabalho e o número reduzido de reincidentes. Os dados apresentados nos fizeram acreditar que essa seria uma proposta positiva no atendimento aos adolescentes a quem se atribui autoria de ato infracional, cumpridores de Medida Socioeducativa de Liberdade Assistida (LA), e fomos motivados a estudá-la.

O forte trabalho de preservação da convivência familiar e comunitária e a avaliação, quase 
sempre positiva, dos adolescentes atendidos e de suas famílias foram também comprovados em pesquisa realizada por Medeiros e Rosa (2007), e confirmam essa percepção.

O levantamento realizado no banco de dados do programa no período que compreende outubro de 2004 a outubro de 2005 constatou que, a partir da inserção e do acompanhamento dos adolescentes pela Casa Sol Nascente, do total de 91 adolescentes atendidos, apenas $13 \%$ (12) deles voltou a praticar ato infracional, enquanto $82 \%$ (74) não mais reincidiram.

O programa foi criado mediante parceria entre a Pastoral do Menor e o Ministério da Justiça, e faz parte do Projeto de Atendimento Integrado à Criança e ao Adolescente da Pastoral do Menor - AICA. A Casa Sol Nascente foi criada em outubro de 2002 para atender adolescentes de ambos os sexos, de 12 a 18 anos, que foram sentenciados com a Medida Socioeducativa de Liberdade Assistida, moradores do Município de Serra. Entretanto, a partir de 2003, o programa passou a atender também os adolescentes sentenciados com a Medida Socioeducativa de Prestação de Serviço à Comunidade por solicitação da juíza da Vara da Infância e Juventude do Município de Serra/ES. A escolha do local para a implantação do programa se deu pelos altos níveis de violência que envolvem os adolescentes e os jovens naquele Município.

\section{Juventude e violência na contemporaneidade}

A violência é um fenômeno multidimensional que se impôs como tema prioritário na agenda pública, principalmente em sua manifestação criminal, que, nos últimos anos, tem atingido a sociedade como um todo e tem feito inúmeras vítimas.
Em meio a tantas formas de violência, aquelas praticadas por adolescentes e jovens têm estado constantemente em debate na sociedade em geral, em decorrência do aumento do número de atos infracionais praticados por esse segmento, especialmente nos principais centros urbanos.

Mas, se, por um lado, os jovens estão engrossando as estatísticas criminais como autores dos delitos, por outro, eles compõem hoje, no Brasil, um triste quadro: o das vítimas.

Ao "integrar-se" ao mundo do crime, através do tráfico de drogas e armas, os jovens têm que seguir as regras impostas: turnos de trabalho, as hierarquias e os códigos de comportamento, entre outros, assumindo todos os riscos provenientes dessa inserção.

Esse mundo é permeado por medo, fugas, torturas, humilhações e mortes. O perigo está sempre por perto, no enfrentamento com a polícia ou com as gangues adversárias. “...As principais vítimas dos crimes violentos são os próprios jovens, principalmente os pobres, por causa da cadeia de vinganças pessoais de que são prisioneiros, especialmente cruel entre os traficantes de drogas..." (Zaluar, 2004, p. 34).

Segundo Zaluar (2004), para o jovem ingressar e ser aceito nas quadrilhas, é preciso provar coragem e ser dono de si, no caso de ter que dominar a vítima ou o inimigo. Entretanto, essa é uma ilusão momentânea de poder absoluto, porque esse mesmo jovem pode ser o objeto da violência de membros de seu próprio grupo, de policiais ou ainda de seus inimigos. O resultado dessa triste realidade está registrado nos dados das pesquisas que apontam assustadores índices de mortalidade dos jovens por armas de fogo. A gravidade do problema tem sido comprovada através das 
Os estudos têm comprovado a importância da família tanto na influência que exerce no engajamento do jovem no mundo da delinqüência

(Ang \& Huan, 2008; Davis, Tang, \& Ko, 2004; Galo \& Williams, 2005) pesquisas que mostram que "...a vitimização letal se distribui de forma desigual..." (Soares, 2004, p. 130). A grande maioria dessas vítimas está na faixa etária de 15 a 24 anos, pertence ao sexo masculino, e são pobres e negros, ou seja, a população jovem é a mais penalizada pela violência, pobreza e exclusão. Essa situação é tão grave que a configuração demográfica registra um déficit de jovens do sexo masculino apenas comparável àquele verificado em sociedades que estão em guerra (Soares, 2004).

Waiselfisz (2005) constatou em sua pesquisa que, das 550 mil mortes por armas de fogo registradas no período de 1979 e 2003, 205.722 , ou seja, $44,1 \%$ foram de jovens na faixa etária de 15 a 24 anos. O crescimento da mortalidade juvenil por armas de fogo no referido período foi constante e progressivo, afirma o autor. A mortalidade entre jovens passou de $7,9 \%$ do total de mortes juvenis, em 1979 , para $34,4 \%$, em 2003, o que significa que um em cada três jovens que morrem no País é ferido por bala.

Toda essa conseqüência negativa da inserção do jovem na delinqüência tem mobilizado pesquisadores do mundo inteiro que buscam compreender tal fenômeno. Os estudos têm comprovado a importância da família tanto na influência que exerce no engajamento do jovem no mundo da delinqüência (Ang \& Huan, 2008; Davis, Tang, \& Ko, 2004; Galo $\&$ Williams, 2005) quanto em processos de recuperação (Branco \& Wagner, no prelo; Brank, Lane, Turner, Fain, \& Sehgal, 2008; Oliveira, 2008; Santos, 2007).

Galo e Williams (2005), ao fazerem uma revisão da literatura a respeito da prática infracional em adolescentes, verificaram que os principais fatores de risco relacionados ao fenômeno são: história familiar em que há baixos níveis de afeto, pouca coesão e ausência de monitoramento das atividades dos filhos e indiferença generalizada nas relações interpessoais. Outras pesquisas também apresentam o envolvimento dos pais em atos anti-sociais como uma característica presente na configuração familiar dos adolescentes autores de ato infracional (Ang \& Huan, 2008; Branco, Wagner, \& Demarchi, 2008).

Davis et al. (2004) explorou, em sua pesquisa com 718 adolescentes chineses, os fatores que provavelmente agem como preditores para o comportamento delinqüente. $\mathrm{O}$ resultado encontrado mostrou que os adolescentes em risco apresentaram mais problemas familiares e um ambiente escolar mais pobre. No entanto, a influência negativa de pares foi o preditor da delinqüência mais relevante encontrado pelo autor entre os jovens estudados.

Ang e Huan (2008) estudaram uma amostra de 772 adolescentes por meio dos seus respectivos relatórios de probation buscando conhecer quais seriam os fatores de risco associados com a reincidência no crime. Os autores verificaram como os mais significativos a criminalidade do pai, a história de fugas de casa, a história de agressão e a pouca idade em que os adolescentes se inseriram na delinqüência. Eles alertam para o fato de que a criminalidade do pai e a pouca idade de inserção na delinqüência são consideradas variáveis "estáticas", porque não estão sujeitas a alteração através de intervenções planejadas. Não obstante, essas variáveis tornam-se importantes para a identificação prévia como fator de risco da reincidência. As outras duas variáveis são consideradas dinâmicas, porque possuem um potencial de mudança a partir de intervenções planejadas.

Em conseqüência, o aumento da participação dos jovens na criminalidade repercute no 
crescimento do número dos que cumprem medidas socioeducativas.

Dados da Secretaria Especial de Direitos Humanos da Presidência da República (SEDH) revelam que o número de adolescentes internados em todo o País passou de 12.051 em 2002 para 15.426 em 2006, o que representa um índice de crescimento de $28 \%$ no período. No Espírito Santo, o número de internos do sistema socioeducativo cresceu $171,3 \%$ no mesmo período, ou seja, bem mais que a média nacional, colocando o Estado em primeiro lugar da Região Sudeste no crescimento do número de internos. Em números absolutos, o Espírito Santo mantinha, no ano 2002, 122 internos na única Unidade de Internação do Estado (UNIS), e, em 2006, esse número passou para 331 adolescentes internos (Brasil, 2006).

A capacidade da UNIS, contudo, não acompanhou o crescimento da demanda. No período de 2004 a 2006, o índice de crescimento foi de apenas $30,1 \%$, o que representa uma capacidade atual para acolher 258 adolescentes (Brasil, 2006). Esse dado indica uma superlotação da Unidade, corroborando dados do Conselho Federal de Psicologia e da Ordem dos Advogados do Brasil. Em 2006, essas duas entidades federais realizaram uma inspeção em várias unidades de internação de todo o País e constataram as precárias condições de instalações em que se encontravam os adolescentes que cumpriam medida socioeducativa em meio fechado (Conselho Federal de Psicologia \& Ordem dos Advogados do Brasil, 2006).

No que diz respeito aos adolescentes que cumprem medida socioeducativa em meio aberto, a SEDH informou somente o número de adolescentes atendidos pelas capitais. Em 2006, eram 209 os adolescentes que cumpriam medidas de prestação de serviço à comunidade (PSC) (15) e liberdade assistida (194), em Vitória, ES (Brasil, 2006).

Nosso estudo apurou que, em Serra, ES foram atendidos 91 adolescentes e jovens no período de outubro de 2004 a outubro de 2005. Constatou-se que $72 \%$ (65) dos adolescentes não concluíram o ensino fundamental e que $51 \%$ (46) dos adolescentes não estavam freqüentando a escola quando praticaram o ato infracional. Outros estudos revelam que a baixa escolaridade está associada à delinqüência (Rosa, Ribeiro Júnior, \& Rangel, 2007; Rydelius, 2001; Volpi, 2002) e estar freqüentando a escola pode ser um fator de proteção do adolescente quando esta fortalece a rede social do educando (Branco et al., 2008).

Além da escolaridade, estudos realizados com a população dos adolescentes atendidos pelos programas socioeducativos no Brasil têm constatado uma inserção precoce do adolescente no mundo do trabalho (Rosa et al., 2007; Volpi, 2002) e uma realidade precária de seus familiares (Priuli \& Moraes, 2007).

Ainda no que se refere aos fatores associados à caracterização dos jovens autores de ato infracional, Carrion e Steiner (2000) encontraram, em uma amostra de 64 adolescentes que cumpriam medida socioeducativa, um percentual de $96,8 \%$ que responderam ter sofrido eventos traumáticos na sua vida.

Estudos sobre o processo de "recuperação" dos adolescentes autores de ato infracional têm apontado sobretudo a importância da formação e do fortalecimento da rede de apoio social dos adolescentes (Rydelius, 2001), com especial atenção para a influência dos pares em sua relações (Brank et al., 2008; Davis et al., 2004) e do bom funcionamento 
familiar (Branco et al., 2008; Brank et al., 2008).

No que se refere à rede de apoio social, Branco et al. (2008) alertam para a importância de os programas que executam as medidas socioeducativas escolherem bem seus operadores. Em estudo realizado pelos autores em um programa de internação com possibilidade de atividade externa no Rio Grande do Sul, os adolescentes quase não citaram os operadores do programa (monitores, funcionários e equipe técnica) na sua rede de apoio social. Os autores acreditam que isso se deva ao fato de que esses operadores estão continuamente cobrando condutas e comportamentos mais adequados dos jovens, o que os fazem vivenciar, quase sempre, relações estressantes.

Em outra pesquisa, Branco e Wagner (no prelo) constataram que, após dois meses de cumprimento de medida socioeducativa com restrição parcial de liberdade, a rede de apoio social dos adolescentes havia se reduzido significativamente. Esse dado confirma a importância de as medidas socioeducativas serem cumpridas em meio aberto e com a participação da comunidade, apesar de ainda prevalecer a idéia de que o banimento do convívio social e o isolamento em territórios de exclusão sejam a melhor alternativa a se oferecer àqueles que um dia infringiram as regras sociais (Gonçalves \& Garcia, 2007).

\section{A proposta pedagógica que fundamenta o trabalho com adolescentes em autoria de ato infracional: a questão socioeducativa}

O Estatuto elenca, no seu artigo 112, as medidas socioeducativas a serem aplicadas aos adolescentes quando verificada a prática do ato infracional. A liberdade assistida é uma das seis medidas previstas no ECA, tendo sido recomendada em Beijing (1985), quando da redação das Regras Mínimas das Nações Unidas para a Administração da Justiça da Infância e Juventude - Regras de Beijing, no intuito de flexibilizar a escolha e evitar ao máximo a institucionalização (Rosa et al., 2007).

No Brasil, essa medida já era adotada pelos Códigos de Menores de 1927 e 1979. No Código de 1927, sua denominação era "liberdade vigiada". No entanto, Rosa et al. (2007) ressaltam que a atual concepção e objetivos que fundamentam a liberdade assistida diferem em muito daquela contida nos Códigos de Menores. Enquanto aquela visava ao controle sobre a conduta do adolescente, a atual medida de liberdade assistida tem por objetivo a criação de condições para reforçar vínculos entre o socioeducando, seu grupo de convivência e sua comunidade.

Brito (2007) nos lembra que o atendimento em liberdade daqueles que foram julgados responsáveis por algum ato infracional se acha relacionado ao conceito de probation. A exemplo do que ocorre hoje, o adolescente que cumpria seu período de probation era acompanhado por um orientador denominado probation officer. Conforme o ECA, o orientador - pessoa capacitada para acompanhar o caso - tem os seguintes encargos:

Art. 119. (...) I - promover socialmente o adolescente e sua família, fornecendo-lhes orientação e inserindo-os, se necessário, em programa oficial ou comunitário de auxílio e assistência social; II - supervisionar a freqüência e o aproveitamento escolar do adolescente, promovendo, inclusive, sua matrícula; III - diligenciar no sentido da profissionalização do adolescente e de sua inserção no mercado de trabalho; IV apresentar relatório do caso. (Brasil, 1990) 
A liberdade assistida poderá ser imposta por prazo mínimo de seis meses, prevista sua prorrogação, revogação ou substituição por outra medida a qualquer momento, desde que ouvidos o Ministério Público, o orientador e o defensor (Rosa et al., 2007).

Ao prever medidas socioeducativas aos adolescentes a quem se atribui autoria de ato infracional, o ECA os responsabiliza pelos seus atos por meio da execução de ações sociopedagógicas. A razão que justifica tais ações é o entendimento, pelo conjunto da sociedade, de que esses jovens são pessoas que estão em um momento especial de suas vidas: estão em processo de desenvolvimento.

A condição peculiar de pessoa em desenvolvimento coloca os agentes envolvidos na operacionalização das medidas socioeducativas a missão de proteger, no sentido de garantir o conjunto de direitos, e educar, oportunizando a inserção do adolescente na vida social. O processo se dá a partir de um conjunto de ações que propiciem a educação formal, profissionalização, saúde, lazer e demais direitos assegurados legalmente. (Volpi, 2002, p. 14)

Para Volpi (2002), "a finalidade maior do processo educacional, inclusive daqueles privados de liberdade, deve ser a formação para a cidadania" (p. 30). E formar para a cidadania implica uma atuação destinada a fazer com que os adolescentes e jovens entendidos como sujeitos de direitos e deveres tenham a possibilidade de mudar sua própria realidade; para que isso aconteça, é imprescindível dar-lhes oportunidades. $\mathrm{Na}$ perspectiva de educar para a cidadania, o conteúdo pedagógico deverá voltar-se para os elementos contidos no Artigo 6o do Estatuto: os fins sociais a que o ECA se dirige, as exigências do bem comum, os direitos e deveres individuais e coletivos, a condição peculiar do adolescente como pessoa em desenvolvimento (Documento Preliminar Para Debate e Aprofundamento citado por Volpi, 2002).

Freire (2006a) afirma que o essencial da Pedagogia da Esperança é que ela, enquanto necessidade ontológica, precisa ancorarse na prática: "Enquanto necessidade ontológica, a esperança precisa da prática para tornar-se concretude histórica" (p. 11). Nessa perspectiva, um projeto pedagógico deve estar articulado a um projeto de sociedade que objetive desenvolver um processo de inclusão que ofereça aos jovens a possibilidade de construir um projeto de vida. É preciso entender, quando falamos em projetos de vida ou projetos sociais voltados para a transformação das pessoas e da sociedade, que eles não acontecem sem que haja vontade e ação dos indivíduos. "O desenvolvimento histórico não se dá espontaneamente, ... é resultante de uma luta estratégica entre grupos, interesses e visões diferentes" (Tassara, 2004, p. 76).

Para Freire (2007), o processo educativo em favor da autonomia dos educandos tem como pressuposto o princípio de que educar é formar indivíduos éticos. A ética defendida pelo autor é aquela que não aceita qualquer forma de discriminação de raça, de gênero ou de classe, assumindo-se como inseparável da prática educativa. "E a melhor maneira de por ela lutar é vivê-la em nossa prática, é testemunhá-la, vivaz, aos educandos em nossas relações com eles" (p.17).

A execução da medida socioeducativa deve obrigatoriamente prever o envolvimento familiar e comunitário. Para que isso ocorra, a estrutura de funcionamento dos programas deve garantir a participação da comunidade nas atividades, no planejamento e no controle das ações desenvolvidas, oportunizando o 
relacionamento entre o adolescente e os membros da comunidade (Volpi, 2002). A convivência familiar e comunitária deve ser garantida em um trabalho que pretende ser socioeducativo e, para isso, é preciso trabalhar permanentemente com a família do adolescente para que ela se comprometa com o processo educativo de seu filho.

\section{Objetivos e método}

O objetivo geral deste estudo foi conhecer a percepção que os operadores da medida de liberdade assistida têm a respeito do seu programa. Os objetivos específicos foram identificar as atividades desenvolvidas pela instituição no atendimento aos adolescentes autores de ato infracional submetidos à medida socioeducativa de LA, conhecer os conceitos de adolescente e de adolescente em conflito com a lei, a proposta pedagógica e as concepções de emancipação, de ressocialização e de protagonismo juvenil que norteiam as práticas desenvolvidas no programa, além dos aspectos facilitadores do processo de acompanhamento dos adolescentes e jovens e os principais entraves para o processo de implementação da medida socioeducativa de LA. Vale ressaltar que não se pretendeu avaliar o programa, somente conhecer a percepção que os próprios operadores tinham dele.

A coleta de dados ocorreu no período de outubro de 2005 a maio de 2006, principalmente por meio de entrevistas semiestruturadas com toda a equipe de operadores (profissionais/educadores) responsáveis pelo atendimento aos adolescentes. Totalizamos seis entrevistas realizadas com seis sujeitos envolvidos na implementação da medida, que foram conduzidas com a ajuda de um roteiro semi-estruturado contendo os tópicos referentes ao objetivo geral e aos objetivos específicos da pesquisa. Os participantes foram contatados e informados sobre os objetivos e sobre a forma como participariam da pesquisa. Foram garantidos todos os direitos éticos, como a manutenção do sigilo, a apresentação dos resultados somente em congressos científicos e em revistas científicas, o direito de interromper a entrevista a qualquer momento e a devolução dos resultados após o término da pesquisa. Estes foram explicitados no Termo de Consentimento, que foi assinado pelos participantes antes do início das entrevistas, que foram agendadas com os participantes em dias e locais definidos de acordo com a disponibilidade e que foram gravadas e transcritas pelos pesquisadores, com duração média de 50 minutos. Os dados coletados foram trabalhados utilizando-se da análise de conteúdo, construindo-se categorias que nortearam a apresentação dos dados (Bardin, 1995). Algumas categorias foram previamente definidas e integradas ao roteiro de entrevista em forma de perguntas. Outras categorias e principalmente algumas subcategorias foram originadas das próprias falas dos sujeitos.

\section{Resultados e discussão}

As percepções dos operadores da Medida Socioeducativa de Liberdade Assistida serão apresentadas a partir de alguns aspectos considerados mais relevantes nas entrevistas: o trabalho em equipe, os aspectos negativos, os positivos, os conceitos de adolescentes/adolescentes em conflito com a lei, a emancipação, a ressocialização, o protagonismo juvenil e a proposta pedagógica.

Os operadores e o trabalho em equipe

No período da realização da pesquisa, a equipe de operadores responsável pelo programa era formada pela coordenadora (assistente social), duas assistentes sociais, uma psicóloga, uma educadora social (assistente social) e uma estagiária (serviço social). 
A formação da equipe teve como marca a identificação com a causa do adolescente. Foi observado que alguns dos integrantes, mesmo não tendo experiência com a área, mostraram-se sensíveis à questão. A identificação com a causa do adolescente aparece como um fator que contribui para qualificar o trabalho. Como afirma uma das entrevistadas, "tem que ser uma pessoa assim, que tenha essa disposição, coragem, sabe, muito amor pra mudar essa história, ajudar o menino a construir esse projeto de vida diferente".

A constituição de uma boa equipe de trabalho começa com uma seleção criteriosa do profissional, que deve ter o compromisso ético-político com a proposta pedagógica e competência profissional para atuar com adolescentes em conflito com a lei. Isso não isenta o aparecimento de problemas, nem permite pressupor que os trabalhadores já estejam definitivamente preparados para os desafios das especificidades do trabalho, mas a equipe do programa demonstra ter consciência das dificuldades e falhas, apresentando disposição para aperfeiçoar o trabalho, como pode ser observado na fala de uma entrevistada: "Nós temos que melhorar muito, mas a gente tá conseguindo fazer esse trabalho".

A equipe apresenta discordâncias em vários aspectos, mas há respeito quanto à opinião do outro, com total liberdade de expressar as questões relativas ao comportamento e aos atendimentos realizados, mesmo que, às vezes, não haja consenso nas discussões. Para todos os entrevistados, essas características contribuem para uma boa avaliação da relação pessoal e profissional entre os membros da equipe.

Um dos entrevistados observou criticamente que, no plano profissional, a idéia de doação pessoal é colocada como questão fundamental e incondicional:

\begin{abstract}
Eu acho que isso continua ligado à questão de ser Pastoral do Menor, eu tenho que me doar. ...Mas eu faço a minha parte na minha comunidade enquanto católica, enquanto cristã, eu tô lá, eu sirvo lá, isso aqui é meu trabalho. ... Eu faço com paixão, ...mas é o meu trabalho, eu quero ser recompensada, ... (ter) reconhecimento. ...Acho que tem que investir mais no profissional, tem que romper essa visão assistencialista.
\end{abstract}

A questão da militância, do "amor à causa" e de ser profissional são fatores de conflito entre os profissionais e a Pastoral do Menor. O comprometimento com o trabalho é fundamental, entretanto, não se pode perder de vista que, antes de tudo, é uma equipe profissional, cujo trabalho deve ser valorizado como tal.

A questão relacionada ao contrato de trabalho dos profissionais tem gerado muita insegurança no grupo, por ser uma relação precária e por tempo determinado, vinculada ao tempo de duração do convênio que mantêm o programa.

A capacitação dos profissionais e a sistematização da experiência foram citadas como uma necessidade, embora estejam propostas no programa. A grande demanda de trabalho foi colocada como a responsável pelo não-cumprimento dessas metas: "Eu acho que devemos avançar na capacitação, não dá pra ficar dizendo ... 'é muito trabalho'..., então vamos lutar por mais profissionais, vamos lutar por mais tempo pra escrever".

Essa percepção dos profissionais está consoante com Freire (2006b), que destaca que 
o papel do trabalhador social que optou pela mudança não pode ser outro senão o de atuar e refletir com os indivíduos com quem trabalha para conscientizar-se junto com eles das reais dificuldades da sua sociedade. Isso implica a necessidade constante do trabalhador social de ampliar cada vez mais seus conhecimentos, não só do ponto de vista de seus métodos e técnicas de ação mas também dos limites objetivos que enfrenta. no seu fazer. (p.56)

Observamos que os profissionais se posicionam criticamente tanto em relação às suas práticas e intervenções com os adolescentes quanto em relação às influências que recebem, principalmente da Igreja, o que caracteriza uma atuação crítica, como a apontada por Freire.

Aspectos negativos

Foi identificado como um dos grandes problemas enfrentados pela equipe a questão da infra-estrutura do programa. O espaço físico foi citado por todos os profissionais como insuficiente e inadequado para atender à demanda de adolescentes.

Com relação aos recursos humanos, foram muito significativas as declarações dos entrevistados, que os consideram reduzidos para realizar um trabalho de qualidade. Declararam que todas as atividades da casa, como o trabalho de secretaria e até a limpeza do local eram realizadas pelos profissionais responsáveis pelo atendimento aos adolescentes: "Aqui nós não temos auxiliar administrativo, ....uuxiliar de serviços gerais. Nós (é) que cuidamos de tudo, nós (é) que limpamos tudo. ...Não é o suficiente, mas estamos aqui tem quatro anos".

As condições de trabalho apareceram como o fator negativo mais citado, já que faltam equipamentos necessários para a realização das atividades com os adolescentes assim como um veículo para a realização de visitas às instituições e aos domicílios. No período de realização da coleta de dados, essas eram todas realizadas por meio do transporte coletivo pelos profissionais: "Os recursos não nos permitem comprar, por exemplo, um DVD. ... F. tinha que trazer o DVD dela portátil de casa, ...o vídeo cassete não funciona, está estragado".

A questão dos salários foi considerada por um profissional como fator negativo, que considera muito baixos em relação ao mercado e que implicam o sentimento de não serem reconhecidos profissionalmente.

Outro aspecto bastante citado como muito presente no cotidiano dos adolescentes e que tem trazido dificuldades ao desenvolvimento do trabalho foi a questão do preconceito e da discriminação. O lugar onde o preconceito aparece mais evidente, segundo os entrevistados, é nas unidades de ensino para as quais os adolescentes são encaminhados para a matrícula e para o cumprimento da Medida de Prestação de Serviço à Comunidade. Afirmam que é preciso sensibilizar a comunidade escolar, "falar do nosso trabalho, falar de nossa pedagogia, ...da necessidade de dar chance, enfim, que ele estava em condição de desenvolvimento". Contudo, não é só na escola que esse preconceito se manifesta. Ele também está presente no Atendimento Integrado à Criança e ao Adolescente (AICA), que é o parceiro da Pastoral do Menor, para onde os adolescentes são encaminhados, a fim de participarem de cursos profissionalizantes. Afirmaram que o preconceito também se manifesta nas empresas, nas comunidades de origem dos adolescentes e até no Conselho Tutelar, que muitas vezes não entendia como parte de sua atribuição atender os adolescentes em conflito com a lei, na aplicação de alguma medida protetora. 
Alguns profissionais citaram como negativo ainda o fato de não haver uma publicação da experiência desenvolvida pelo programa e a demora do encaminhamento do projeto para a garantia do recursos no orçamento.

Aspectos positivos

Entre os aspectos positivos para o desenvolvimento do trabalho que mais apareceu nas falas das entrevistadas, foi o de existir uma boa proposta pedagógica, uma equipe responsável pela sua concretização e a coordenação ser realizada por um profissional que tem uma história de militância e experiência nas questões relativas ao segmento infanto-juvenil. O perfil dos profissionais que constituem a equipe de trabalho se identifica com a causa dos adolescentes, e a forma como os adolescentes são acolhidos e tratados na casa foram destacados como fatores que favorecem o desenvolvimento do programa. Isso aponta outro aspecto, que é o da confiança e a aceitação que os adolescentes e seus familiares depositam na equipe. Assim, afirmaram que os próprios adolescentes fazem propaganda positiva do programa para os outros adolescentes. As visitas semanais realizadas na Unidade de Internação Provisória (UNIP) e na Unidade de Internação (UNIS) por integrantes da equipe foram citadas como fator positivo para o processo de trabalho com os adolescentes que, quando têm a progressão da medida, chegam ao programa conhecendo alguns profissionais, o que facilita a aproximação entre eles.

A rede de serviços, como as escolas, postos de saúde, Conselhos Tutelares, associações de moradores, entre outros, também foi destacada como muito importante no sentido de dar suporte ao programa, apesar das dificuldades encontradas, como já mencionamos anteriormente.
A aceitação e a acolhida da comunidade local foram consideradas extremamente importantes por todos da equipe.

Conceito de adolescente / adolescente em conflito com a lei

Alguns dos entrevistados basearam-se na definição de adolescente contida no Estatuto, ou seja, a pessoa que tem entre 12 e 18 anos incompletos e que está em processo de desenvolvimento físico, psicológico, entre outros, sendo, portanto, portadora de direitos e deveres, merecedora de proteção integral, apoio familiar e comunitário.

As concepções presentes nas falas dos profissionais refletiram uma diversidade de possibilidades de ser adolescente nos aspectos físico, emocional, psicológico e social. Percebem que a adolescência é um processo complexo em que muitas dimensões devem ser consideradas, e demonstram que a fase da adolescência pode ser um período de crises e conflitos mas também de possibilidades de mudanças e de questionamentos fundamentais para $\mathrm{o}$ desenvolvimento da sociedade.

Todos destacaram que os adolescentes em conflito com a lei "são como todos os demais adolescentes", que têm conflitos, inseguranças, medos. O que pode diferenciar esses adolescentes dos demais, segundo os entrevistados, é que tiveram menos oportunidades, não tiveram seus direitos básicos garantidos pelas políticas públicas e que, em função de sua situação social, financeira e familiar, cometeram ato infracional. Portanto, são adolescentes que estão em conflito com a lei, mas não estão eternamente na condição de infratores, respondendo por seus atos por meio das medidas socioeducativas. 
Outras respostas enfatizaram que esses adolescentes não tiveram uma base familiar que lhes oferecesse uma presença afetiva forte, com estabelecimento de limites e regras de boa convivência. A história de vida marcada por "envolvimentos" em atos ilícitos fez com que eles perdessem suas vidas através da violência e da banalização da vida. Dessa forma, alguns entrevistados afirmaram que esses adolescentes precisam de mais atenção que os outros.

Segundo Gomes da Costa (1991), caracterizar os adolescentes autores de ato infracional ou com outro tipo de dificuldade pessoal ou social através do que os torna diferentes de outros jovens só faz aumentar as suas dificuldades, sejam emocionais, cognitivas ou outras. O mais importante nesse processo relacional é valorizar as capacidades e potenciais do adolescente e do jovem; o trabalho educativo deve estruturar-se nos atributos positivos dos jovens, ou seja, "o que ele é, o que ele traz, o que ele sabe, o que ele é capaz" (p. 61). Isso pressupõe romper as concepções adultocentristas, em que o parâmetro é sempre o adulto (Ozella, 2002).

\section{Emancipação}

No entendimento de alguns entrevistados, o processo emancipatório do adolescente se torna possível por meio do diálogo, da preparação para o discernimento do que é bom e do que não é para sua vida.

Segundo Freire (2003), por meio do diálogo, é restabelecido o direito de o ser humano se inserir no mundo, transformá-lo e humanizarse. O diálogo pressupõe compromisso com os homens, um compromisso amoroso, ético, humilde, grávido de fé e de esperança na humanidade e nas suas possibilidades de libertação.
Na pesquisa, foi identificado também o fato de a emancipação se iniciar quando o adolescente busca protagonizar sua própria vida através de melhor convivência com a família, inserindo-se, por exemplo, em cursos profissionalizantes e também quando começa a sonhar com sua liberdade, fazendo planos para o futuro.

Na perspectiva emancipadora defendida por Gomes da Costa (1991),

\begin{abstract}
Sem ignorar as exigências e necessidades da ordem social, o educador não somente aceita a perspectiva de que sua função venha a ser apenas adaptar o jovem a isso que aí está. Ele vai mais longe. Ele quer abrir espaços que permitam ao adolescente tornar-se fonte de iniciativa, de liberdade e de compromisso consigo mesmo e com os outros, integrando de forma positiva as manifestações desencontradas de seu querer-ser. (p. 20)
\end{abstract}

\section{Ressocialização}

Os entrevistados afirmaram não gostar e não concordar com o termo "ressocialização", pois fica parecendo que "a pessoa saiu da sociedade e vai voltar". Foi-lhes informado que o programa trabalha a ressocialização do adolescente, buscando mudar o seu comportamento na sociedade e enfatizando os valores cristãos, moral e ético através da realização das oficinas, dos atendimentos individuais e grupais, dos filmes, livros, apostilas e passeios. Esse processo de "ressocialização" começa a ser percebido pela equipe quando o adolescente muda sua conduta diante da vida e começa a acreditar que pode mudar visualizando propostas para o seu futuro, lutando e traçando planos.

Faleiros (2004) prefere falar em "inserção social", e considera-a 
como processo de mudança das relações em um campo em que (o) próprio ator social se torna protagonista de seu destino e, portanto, passa a ter a afirmação de sua identidade enquanto cidadão, enquanto pessoa, e reconhecimento efetivo nas oportunidades do dia a dia para expressarse e conseguir sobreviver dignamente, numa sociedade que estabelece critérios de inclusão e exclusão, mas também de solidariedade, respeito às diferenças e acesso às condições de vida. (p. 92)

Protagonismo juvenil

Quanto ao protagonismo juvenil, foi destacado que esse processo se inicia quando começa a ser trabalhado com o adolescente a questão do "sujeito", como ele se percebe e como ele percebe o mundo. Por meio do diálogo constante com o adolescente, é possível capacitá-lo para o conhecimento de seus direitos para que tenha vez e voz, ou seja, para que possa participar e tomar decisões e ser protagonista de sua própria história.

Foi afirmado também que o programa possibilita a participação dos adolescentes nas decisões relativas à casa mediante a elaboração das regras que estabelecem os direitos e os deveres dos participantes, quando avaliam as atividades no decorrer da medida e quando são desligados, passando a ser chamados para contribuir com sugestões que visem à melhoria do programa.

O protagonismo juvenil é entendido como a efetiva participação dos adolescentes nos processos de decisão na vida da comunidade em que possam contribuir com as soluções para os problemas que os afetam. Uma das características do protagonismo juvenil é o exercício de direitos e deveres nas várias esferas da vida social.

Para Gomes da Costa (2004), "uma ação é dita protagônica quando, na sua execução, o educando é o ator principal no processo de seu desenvolvimento". Costa (2001, p. 9) utiliza o termo protagonismo para designar "a participação de adolescentes no enfrentamento de situações reais na escola, na comunidade e na vida social mais ampla".

Proposta pedagógica

Com relação à concepção de trabalho pedagógico, foi ressaltado que o profissional precisa entender que o adolescente tem uma história, tem seus valores, sua cultura, e, assim, o trabalho deve ter como ponto de partida a vivência do adolescente. É fundamental compreender os motivos que o levaram a cometer o ato infracional. Um ponto muito destacado pelos entrevistados foi a questão da acolhida do adolescente ao entrar no programa, que deve ser diferenciada para que Ihe seja propiciado um ambiente acolhedor, afetivo.

O trabalho pedagógico, na perspectiva dos operadores da medida, deve ser baseado no diálogo, na presença, na escuta do que o adolescente tem a dizer sobre a orientação, os valores, o limite e a espiritualidade. Isso corrobora a idéia de Gomes da Costa (1991), segundo a qual "fazer-se presença construtiva na vida de um adolescente em dificuldade pessoal e social é, pois, a primeira e a mais primordial das tarefas de um educador que aspire a assumir um papel realmente emancipador na existência de seus educandos" (p. 18). Para o referido autor, a presença é uma necessidade básica fundamental para que o educando supere suas dificuldades pessoais e possa se reconciliar consigo mesmo e com os outros. Fazer-se presente na vida do educando no de sentido que ele possa satisfazer suas necessidades de estima, isto é, sua imperiosa necessidade de sentir-se compreendido e aceito deve ser a meta do educador. 
Nesse sentido, Faleiros (2004) adverte que

a preocupação com o projeto pedagógico, do ponto de vista progressista, é quanto a sua capacidade em garantir, realmente, um desenvolvimento do jovem que Ihe permita superar as condições que deram origem ao delito e ampliar as trocas sociais para um adequado processo de equilíbrio entre a convivência social e a autonomia individual. (p. 90)

Atividades desenvolvidas

A partir das entrevistas, foi possível identificar o desenvolvimento de uma série de atividades realizadas pela equipe. Algumas são realizadas no espaço interno da casa, como os atendimentos individuais aos adolescentes e a seus familiares, os trabalhos de grupo, como os grupos de vivência, os trabalhos de planejamento, organização e elaboração de documentos, os grupos de estudo, as reuniões de equipe e os encaminhamentos, entre outros.

O grupo realiza também muitas atividades externas imprescindíveis para efetivar o programa. Como exemplos, foram citadas as visitas às associações de moradores, às escolas, aos postos de saúde, aos Conselhos Tutelares, ao Juizado, à Prefeitura e a outras instituições. Essas visitas têm como objetivo a sensibilização, a articulação da rede de serviços e o estabelecimento de parcerias visando a garantir o atendimento dos direitos dos adolescentes, além de atividades de lazer e cultura, como a visita ao Parque Pedra da Cebola para assistirem a um show do grupo capixaba "Moxuara".

\section{Considerações finais}

O perfil do profissional comprometido com a proposta de trabalho e com o adolescente foi destacado como fundamental para o sucesso do programa. Percebemos que esse comprometimento articula razão e emoção no desenvolvimento da proposta pedagógica, tendo em vista que há uma identificação com a história de vida dos adolescentes e com sua origem social. Aqueles profissionais afirmaram acreditar no potencial positivo dos adolescentes para mudar o rumo de suas vidas, o que, conforme os autores citados neste trabalho, é fundamental em uma proposta de trabalho pedagógico, já que acreditar é ter esperança, é apostar no outro.

O conhecimento da realidade do adolescente que tem uma história, tem valores, tem a sua cultura, é considerado na proposta de atendimento direcionado a eles. No desenvolvimento da proposta pedagógica, foi colocada pelos profissionais a importância que é dada à acolhida, à presença, à escuta, ao diálogo no relacionamento com o adolescente, à educação solidária, ao espírito crítico, à criatividade e ao protagonismo, que são os princípios norteadores da proposta de trabalho. Para Freire (1999, p. 153), "testemunhar a abertura aos outros, a disponibilidade curiosa à vida, a seus desafios, são saberes necessários à prática educativa".

Pode-se perceber que é objetivo do programa sensibilizar a comunidade e a família do adolescente, envolvê-las nas atividades desenvolvidas para que contribuam com o processo de reinserção do adolescente e para que se supere a visão preconceituosa e estigmatizante sobre ele.

O programa conseguiu construir um relacionamento muito bom com a comunidade local, que está sensibilizada com relação aos adolescentes atendidos pela casa, e, muitas vezes, tem contribuído com o trabalho. As comunidades de origem do adolescente nem sempre o acolhem, em razão do preconceito e 
também do medo, já que muitos adolescentes têm um grande envolvimento com o tráfico de drogas e com outras ações violentas nos bairros. Nesse sentido, há muita dificuldade de sensibilizar pessoas nas comunidades para atuarem como orientadores voluntários dos adolescentes. Nesses casos, a própria equipe tem realizado os acompanhamentos dos adolescentes nos vários espaços em que está inserido.

Há uma preocupação recorrente da equipe com as articulações das redes de serviço e das parcerias, que ainda são frágeis e que são fundamentais para garantir os encaminhamentos dos adolescentes para a efetivação de seus direitos. Essas articulações garantem o princípio da incompletude institucional, fazendo com que o programa se articule politicamente com diversos parceiros na defesa dos direitos do adolescente e, em conseqüência, da população como um todo.
Alguns profissionais se posicionaram criticamente quanto ao fato de o programa ser vinculado à Pastoral do Menor. Essa condição, se, por um lado, abre espaços pela credibilidade que conquistou na sociedade por meio de suas ações direcionadas ao segmento infanto-juvenil, por outro, cria a expectativa, em relação ao profissional, de uma doação incondicional, acima de qualquer outro interesse que não a causa do adolescente. Esse fato tem causado descontentamento e sentimento de desvalorização dos profissionais que, mesmo identificados com as causas sociais e tendo capacidade de suportar frustrações sem desqualificar o trabalho junto aos adolescentes, com o passar do tempo, podem desanimar. Em conseqüência do desânimo, esses profissionais correm o risco de deixarse abater pela desesperança e, portanto, de verem geradas conseqüências negativas para o desenvolvimento do trabalho.

\section{Maria Emília Passamani}

Mestre em Política Social pela UFES. Professora do Departamento de Serviço Social da Universidade Federal do Espírito Santo.

\section{Edinete Maria Rosa*}

Doutora em Psicologia Social pela USP. Professora do Departamento de Psicologia Social e do Desenvolvimento e dos Programas de Pós-Graduação em Psicologia e Política Social da Universidade Federal do Espírito Santo.

*Endereço para envio de correspondência:

Universidade Federal do Espírito Santo, Programa de Pós-Graduação em Psicologia, Campus Universitário de Goiabeiras, Av. Fernando Ferrari, 514, Vitória - ES - Brasil, CEP: 29075-910

E-mail: edineter@gmail.com 


\section{Referências}

Ang, R. P., \& Huan, V. S. (2008). Predictors of recidivism for adolescent offenders in a Singapore sample. Criminal Justice and Behavior, 35(7), 895-905.

Bardin, L. (1995). Análise de conteúdo. Lisboa: Edições 70.

Becker, D. (2003). O que é adolescência. São Paulo: Brasiliense.

Branco, B. de M., \& Wagner, A. (no prelo). Os adolescentes infratores e o empobrecimento da rede social quando do retorno à comunidade. Ciência \& Saúde Coletiva.

Branco, B. de M., Wagner, A., \& Demarchi, K. A. (2008). Adolescentes infratores: rede social e funcionamento familiar. Psicologia: Reflexão e Crítica, 21(1), 125-132.

Brank, E., Lane, J., Turner, S., Fain, T., \& Sehgal, A. (2008). An experimental juvenile probation program: Effects on parent and peer relationships. Crime \& Delinquency, 54(2), 193-224.

Brasil. (1990). Estatuto da criança e do adolescente (Lei Federal no 8.069). São Paulo: Imprensa Oficial do Estado de São Paulo.

Brasil. Secretaria Especial dos Direitos Humanos. (2006). Levantamento Nacional do Atendimento Socioeducativo. Brasília. Recuperado em 25 de setembro de 2008, de http://www.presidencia.gov.br/estrutura presidencia/sedh/ spdca/sinase/

Brito, L. M. T. de. (2007). Liberdade assistida no horizonte da doutrina da proteção integral. Psicologia: Teoria e Pesquisa, 23(2), 133-138.

Carrion, V. G., \& Steiner, H. (2000, March). Trauma and dissociation in delinquent adolescents. Journal of the American academy of child and adolescent psychiatry, 39(3), 353-359.

Conselho Federal de Psicologia \& Ordem dos Advogados do Brasil. (2006). Um relato das unidades de internação de adolescentes em conflito com a lei. Brasília, DF.

Costa, A. C. G. (2001). Tempo de servir: o protagonismo juvenil passo a passo; um guia para o educador. Belo Horizonte: Universidade.

Davis, C., Tang, C., \& Ko, J. (2004). The impact of peer, family and school on delinquency. Internationalizing Social Work Education, 47(4), 489-502.

Faleiros, V. P. (2004, March). Impunidade e imputabilidade. Revista Serviço Social e Sociedade, 24(77), 78-97.

Freire, P. (1999). Pedagogia da autonomia. Rio de Janeiro: Paz e Terra.

Freire, P. (2003). Pedagogia do oprimido (35a ed.). Rio de Janeiro: Paz e Terra.

Freire, P. (2006a). Pedagogia da esperança: um reencontro com a pedagogia do oprimido (13a ed.). Rio de Janeiro: Paz e terra.

Freire, P. (2006b). Educação e mudança (29a ed., M. Gadotti \& L. Lopes Martin, Trads.). Rio de Janeiro: Paz e Terra.

Freire, P. (2007). Pedagogia da autonomia: saberes necessários à prática educativa (35a ed.). São Paulo: Paz e Terra.

Galo, A. E., \& Williams, L. C. de A. (2005). Adolescentes em conflito com a lei: uma revisão dos fatores de risco para a conduta infracional. Psicologia: Teoria e Prática, 7(1), 81-95.

Gomes da Costa, A. C. (1991). De menor a cidadão. Brasília, DF: Centro Brasileiro para a Infância e Adolescência; Ministério da Ação Social.
Gomes da Costa, A. C. (2004). O adolescente como protagonista. In Associação Brasileira para o Desenvolvimento de Lideranças. Recuperado em 13 de março de 2006, dehttp://www.bireme. $\mathrm{br} / \mathrm{bvs} /$ adolec

Gonçalves, H. S., \& Garcia, J. (2007). Juventude e sistema de direitos no Brasil. Psicologia: Ciência e Profissão, 27(3), 538-553.

Medeiros, F. S. A., \& Rosa, E. M. (2007). Caracterização dos adolescentes que cumpriram medida socioeducativa de liberdade assistida no município de Serra/ES nos anos 2002 a 2006. In Associação Brasileira de Psicologia Social (Org.), Resumos, V Encontro Regional de Psicologia Social (p. 60). Vitória: GM.

Oliveira, M. B. de. (2008). O significado da violência para jovens de classe média autores de ato infracional. Dissertação de Mestrado em Política Social, Universidade Federal do Espírito Santo, Vitória.

Ozella, S. (2002). Adolescência: uma perspectiva crítica. In M. de L. J. Contini, S. H. Koller, \& M. N. dos S. Barros (Orgs.), Adolescência e psicologia: concepções, práticas e reflexões críticas (pp. 16-24). Brasília, DF: Conselho Federal de Psicologia.

Priuli, R. M. A., \& Moraes, M. S. de. (2007). Adolescentes em conflito com a lei. Ciência \& Saúde Coletiva, 12(5), 11851193.

Rosa, E. M., Ribeiro Junior, H., \& Rangel, P. C. (2007). O adolescente, a lei e o ato infracional. Vitória: Edufes.

Rydelius, P. A. (2001). Antisocial behavior of adolescentes and environment: Need for a multidisciplinary model. Lakartidningen, 98(19), 2313-2316.

Santos, F. V. G. D. (2007). Família: peça fundamental na ressocialização de adolescentes em conflito com a lei? Dissertação de Mestrado em Psicologia Clínica, Universidade Federal de Pernambuco, Recife. Recuperado em 22 de abri de 2008, de http://www.unicamp.br/tede//tde/arquivo. php? $\operatorname{cod}$ Arquivo $=126$

Soares, L. E. (2004). Juventude e violência no Brasil. In R. Novaes \& P. Vannuchi (Orgs.), Juventude e sociedade: trabalho, educação, cultura e participação (pp. 130-159). São Paulo: Fundação Perseu Abramo.

Tassara, E. T. de O. (2004). Avaliação de projetos sociais: uma alternativa política de inclusão? In L. de Souza \& Z. A. Trindade (Orgs.). (2004), Violência e exclusão: convivendo com paradoxos (pp. 75-104). São Paulo: Casa do Psicólogo.

Volpi, M. (2002). O adolescente e o ato infracional (4a ed.) São Paulo: Cortez; UNESCO.

Fundo das Nações Unidas para a Infância. (2002). Relatório da situação da adolescência brasileira. Brasília, DF: Autor.

Zaluar, A. (2004). Integração perversa: pobreza e tráfico de drogas. Rio de Janeiro: Editora FGV.

Waiselfisz, J. J. (1998). Juventude, violência e cidadania: os jovens de Brasília. Brasília: UNESCO, Cortez.

Waiselfisz J. J. (2005). Mortes matadas por armas de fogo no Brasil. Brasília, DF: UNESCO. 